\title{
Nanotechnology and Food. Is Nanotechnology for Food Applications Safe? : A Review
}

\author{
Rahmat A. Khan ${ }^{1 *}$, Noor M. khan ${ }^{1}$, Azhar Nisar ${ }^{2}$ \\ ${ }^{1}$ Department of Biotechnology Faculty of Biological Sciences, University of Science \& Technology Bannu (USTB), KPK, Pakistan \\ ${ }^{2}$ Department of Industrial Biotechnology, Government College University (GCU) Lahore, Punjab, Pakistan
}

Received: November 18, 2015; Accepted: December 31, 2015; Published: December 31, 2015

*Corresponding author: Rahmat A. Khan, Department of Biotechnology Faculty of Biological Sciences, University of Science \& Technology Bannu (USTB), KPK, Pakistan, E-mail: rahmatgul_81@yahoo.com

\begin{abstract}
Food nanotechnology is a combined discipline of food science and nanotechnology. It provides many applications almost in all areas of food technology. This article reviews the main focus in food nanotechnology research of food safety in various forms in which nano-biosensors and antimicrobials nano-agents are the works of interest. These tools are helpful in providing food security and together with nano-coating materials. It makes the base of smart packaging. It is now being estimated from the review that these nanoagents have great contribution in food safety but the health hazard risks due to accumulation of nanomaterials in food should also move parallel to these tools.
\end{abstract}

Keywords: Nanoparticles; Biosensors; Food packaging; Nano coating

\section{Introduction}

In the past decade there has been advancement in material sciences in which a concept rises and acquires a name called "Nanotechnology". Despite the fact that the concept of nanotechnology seems new but, technically its applications have been used since many years which was a part of hidden knowledge that came under consideration few years back. Although the concept of nanotechnology seems technically new, there are applications in use from many years. The term "nanotechnology" can be defined asthe science and study of nano-materials having size ranging from 1 to $100 \mathrm{~nm}$, because a matter at this size has properties which impart them unique abilities that can't be possibly acquired by larger one of the same matter [1]. The nanotechnology has been existed since the life came into existence as it can clearly be observed in the expression of DNA into nano size proteins and carrying out functions at small scale yet giving a huge impact on the whole organism is that how we can explain the beauty of nanotechnology [2]. We are applying the knowledge of nano-tech in our life by using materials of nano size and gaining some benefits from it. Among many other applications and advances, nanotechnology makes its way to give an impact in food science also and much other advancement came up with the combination of food science and nanotechnology arising a new emerging discipline called food nanotechnology. Literally Food and Drug Administration USA (FDA) gives the definition of food nanotechnology in a sense that the nanomaterials used in this case can have size up to $1000 \mathrm{~nm}$ because there has been some evidences that even at larger size the particles have same behavior at smaller scale [3].

The technology provides its services in almost all sectors of food from production to marketing. In agriculture sector there are several applications available like nano-tech based pesticides and fertilizers with effective impact on plant growth, targeted genetic engineering and molecular farming with the help of nano-vectors which is hoping to take the place of viral vectors [4]. In food processing various industries are also taking leads and making the food with better quality and good nutritive value by utilizing the knowledge of nanotechnology and applying it in food sciences. For example, high impermeable packaging nanomaterials are used for protection of food from UV radiations and providing more strength to keep the food protected from outer environment, thus increasing their shelf life. Beside, nanosensors are also used for the detection of chemicals, gases and pathogens which can represent the spoilage and its rate. In modern terminology a word is given to such type of packaging which is known as smart packaging. Nutritive supplements using polymeric nano-coating with greater bioavailability are also introduced to complete the nutritional requirements. And it is a fact that the most participating research in food nanotechnology is in food processing section in which many researchers and industries are increasing their research in food safety with the help of nanotechnology. Some studies suggested that people are not accepting the direct involvement of nano-particles in food [5] due to some risk factors. So it is needed to provide some safety measurements by creating methods that avoid such direct involvement to reduce the risk and satisfy the community.

\section{Organization of Food Structure at Nano-Level}

Nanoparticles are not always synthetic but nature provide us a view of thinking how these particles are present in nature in various forms as in food, which is a combination of nano versus micro-particles. These molecules make an ordered organization 
from liquid, emulsions, gels, fibers and cells and combine giving a multi structured food mega particle. Taking an example of cow's udder as micro versus nano structured natural device, in which casein micelles and fat globules give their combination for making a nano versus micro structured milk. The casein micelles range in size from 300-400 nm while fat globules have a range from 100 $\mathrm{nm}-20 \mu \mathrm{m}[6]$. This is a fact that what we eat is converted into nano structure after it is assimilated and digested. Proteins converted into amino acids, lipid and sugars are hydrolyzed making a nano molecule to be metabolized efficiently. The Nanoparticles are either present in food naturally or sometimes it arises due to natural events like changes in $\mathrm{pH}$, temperature etc. For instance, in yogurt formation, which is based on micro and nano technology, the smaller structure like native beta lactoglobulin, having size about $3.6 \mathrm{~nm}$ undergo deterioration and form a larger structured fibrils which in turn form a gel like yogurt structure [7]. In mayonnaises, nano structured fat layers combine with protein globulins creating a food structure. The starch depositions in food are itself a combination of smaller glucose molecules. Starch nano crystal that is amylose region crystals with size about 10-20 $\mathrm{nm}$ can be used as bioactive materials. It has been reported that $\alpha$-lactalbumin from milk hydrolyzes and form nanotubes, which by assembly gains the ability to carry nutritional, pharmaceutical and other supplementary roles [8].

The food formulations, additives and recipes are used for making some structural changes like crystallization, giving clarity to juices, vitrifications, and structure or network formulations to make end stable structure of food. Literature shows that decreasing diameter of particles increases the surface area after combinations, at nano scale the virtual molecular forces like hydrogen bonding, van der Waals forces, and other interactions becomes dominated comparatively, therefore it is predicted that if additives used in food formulation at nano size, it would make the assembly and the process more efficient [9]. Research has been conducting in naturally occurring nano structures that can be used as additives which is also used to focus on changing the naturally occurring food substance into nano one to modify its functionality accordingly different and efficient as the originals. Literature gives us important examples of titanium oxides and silicon dioxide which has been used nanomaterials [10]. Not only this, but it should also be considered that reducing size causes increase in the reactivity and may cause disturbance to biological structures which in bigger size doesn't occur. The risk area of food nanotechnology is not yet been well developed, but to provide safe food this area should also be elaborated.

\section{Nanomaterials as Biosensors in Food Safety}

Fresh food, if not consumed readily, it can be stored by packaging keeping in view that it should be consumed within a specific period of time otherwise it is estimated that it would not be consumable. Open fresh food possesses certain characteristics when they spoil that are changes in odour, texture, taste etc. But these properties are hidden in case of packed food so the consumer only relies on the sell by date tag on the packed food provided by the manufacturer, but it is only applicable in certain conditions in which it should be stored otherwise it may change the date of expiry. These conditions often vary in transportation and storage of food in ware houses. So, it becomes difficult to analyze the freshness by consumer in packed food. The nano biosensors provide an overcome to this problem [11]. Nanotechnology brings some advancement in quality control and analysis of food to provide food safety by introducing nanotechnology based biosensors and detectors. These are designed by combination of nanotechnology with several other technologies to detect and sense components for which a sensor is being designed like detection of pathogens, various pollutants, and detection of chemicals, gases and food spoilage. In some countries biosensors are already been associated with packaging [12]. As compared to high cost techniques like gas chromatography-mass spectroscopy, electronic noses and solid state detector, nano technology provides low cost and fast method of detection by using simple chemically reactive dye system coated with some immobilization and gel-matrices [13]. The biosensors are designed by combination of various systems like electro-chemically attached imunosensors for detection of pathogens or spoilage causing microorganisms, enzyme linked carbon nano tubes for detection of chemicals which could be toxic or environmental pollutants [13]. Food quality assurance should be analyzed in all stages from production to storage, and it should be done as fast as possible. Nanotechnology based biosensors provide a cheap, fast, highly selective and portable tool for detection of food quality and its measurements [14].

\section{Detection of chemicals}

Nowadays, using the knowledge of analytical chemistry it is easy to detect various chemicals, pollutants and some chemical components with the help of nanomaterials in which various combinations are used to provide food safety measurements in food quality control. For example, Gold Nanoparticles (AuNPs) with cyanuric acid [15] give red color when treated with some raw milk samples without melamine but in some samples due to the presence of a milk contaminant, melamine, this assay gives blue color and the intensity of color gives information about the concentration of melamine [16]. In some other experiments the results were the same that was color change due gold nanoparticles but with some other chemical reductants for the detection of melamine [17]. Apart from this color change detection some fluorescence based assays are also developed like enhanced fluorescence linked immuned sorbent assay (EFLISA) which is used to detect the presence of gliadin, which is inflammation causing agents in patients of celiac disease. The system is based on rhodamine labeled anti-gliadin antibodies with nano silver films (NSFs). This system utilizes metal enhanced fluorescence due to rhodamine [11]. Some other same kind of fluorescent based nanomaterials detect cyanides in drinking water using cluster of quenched gold Nanoparticles [18] and detector using liposomes at nanoscale that also detect toxic pesticides in water [19]. Nanomaterials for detection of pretentious bacterial toxins are also been invented for detection of botulinum toxin using antibody labeled nanosystem [20].

Not only biological and chemical systems are involved in designing of these detectors but also nano level electrical system 
is involved and these electrochemical nano devices are vastly used for analytical purpose. Some electrochemical devices which are imunosensors along with cerium oxide nanoparticles and chitosan nanocomposites using nanowire based transistors and carbon nanotubes which detect several toxins like staphylococcal enterotoxin [21] and cholera toxin [22]. These detector systems at nano level have an advantage that they are able to detect impurities, pollutants and toxic chemicals in very low quantity even at nanolevel [23].

\section{Detection of gases}

Gases trapped during food packaging like oxygen, carbon dioxide or moisture also leads to the spoilage of food. But it is not possible to check the gases level inside the package without unsealing or damaging the pack. So the presence of gases are most of times analyzed by checking one of the food pack out of hundreds of packages passed from a single process. Which is not that much reliable process but still it is time consuming and one cannot check whole of the batch at a time. The nanotechnology based techniques now making it possible to identify the content of specified gas inside the packed food at a single look by simply coat the nanobiosensor materials in packaging which detect the amount and type of gas and moisture content inside the packed food [24]. Nano sized $\mathrm{TiO}_{2}$ and $\mathrm{SnO}_{2}$ particles in combination with methylene blue; a red-ox active dye is introduced which is a photoactive ink used in packages for detection of oxygen inside containers. These materials gradually changes colors in response to oxygen present [24]. This do not gives the precise information about the quantification of oxygen but it can give an easy visual analysis for consumer to check the level of gases. In some other cases the moisture content is measured and analyzed by carbon coated nano copper particles that are dispersed polymerically on tenside strips [25]. In the presence of humidity the polymer matrix tends to swell up due to the separation of the coated nanoparticles. These changes cause to produce various colors that can be easily measured [26]. Some other discoveries lead to the detection of gases like gaseous amines by nanofibrils of perylenebased fluorophores in fish and meat products, also detection of organic compounds like acetone, ethanol, and some non-organics like carbon mono oxides with the help of an electronic nano sensor composed of nano $\mathrm{SnO}_{2}$ and micro particles of $\mathrm{TiO}_{2}$ [27] and by the replacement with $\mathrm{WO}_{3}-\mathrm{SnO}_{2}$ nanocomposites the device may able to detect the presence of ethylene [28].

\section{Detection of microorganisms}

Nanotechnology provides quick and reliable methods to detect the infectious agents with the help of nanomaterials acting as sensor devices. These strategies are the same as the conventional bioassay detection systems like enzyme linked immuno assays but the scale is being reduced from micro to nano level. The use of nanoparticles for pathogenic microorganism detection gives an ideal fast strategy to identify the target microorganisms [29]. Some metallic particles such as gold and silver particles conjugated with short specific oligonucleotides strands can bind with specific strands of DNA present and detectable by color change [30-31]. These metallic nanoparticles can also be conjugated with antibodies for detection of proteins, bacteria, viruses and some other allergens. Apart from these nanoparticles, there was a common trend for using magnetic Nanoparticles from a long time which is still a method of interest. In such system a paramagnetic nano particle like iron, as magnetic contrasting agent, together with a detecting system of enzyme, oligonucleotide, or antibody for Magnetic Imaging Resonance (MRI). These systems are also used to detect microorganisms and other their moieties [32]. Detections with magnetic Nanoparticles are also achieved by Superconducting Quantum Interference Devices (SQUID), which is responsible to record the abnormal changes in the magnetic properties upon interaction with other molecules [33]. Carbon nanotubes are also used for pathogenic detection with same strategy linked with several other entities [8].

\section{Nanotechnology in Food Packaging}

\section{Nano-coating}

Nowadays, it is a demand to preserve the food as much longer as possible. In most cases if we are using packaging technologies then we aim to protect the food from gases, environmental hazards, insects and specially from microbial contaminations and although today's food packaging techniques provides promising results, but this is facilitated when the concept of smart packaging is developed. It is also known as active and intelligent packaging. This involves the coating of different agents like oxygen trappers, moisture absorbers, sensory agents, flavor releasing systems, indicators and packaging with antimicrobial coatings [34].

Polymer nanotechnology is a broad interdisciplinary area of research being used in food packaging due to the broad demand of future generation. Biological nano-composites have multiple properties but the most important aspect of polymer nanomaterial is the improvement of mechanical, chemical strength and gases barrier properties $[35,36]$ with the elaboration of this facts we can say nanomaterial preserve food, prevent from deterioration, $[37,38]$, maintain quality of the food, extending shelf life of the food providing strength, stiffness and barrier to gases like $\mathrm{O}_{2}$ and $\mathrm{CO}_{2}$ light and moisture [39]. The use of nano-protectant not only preserve and secure food but also decrease the general use of non-degradable plastic which is a concern problem not only to human but also to the aquatic environment, [38] thus help to keep safe the world [40].

It is already being explained that if fresh food like fruits, vegetables, beverages, dairy and bakery products are not preserved and protected after their generation then it might be demolish because of oxidation, reduction, dehydration, losses of flavor, vitamins, minerals and soon. Therefore, proper preservative techniques are essential especially Polymer Nanomaterials Packaging (PNP) and nanocoating or nanolamination. There are numerous nanomaterials which have distinct properties and uses. Polymer Nanomaterial for Food Packaging (PNFP) is divided in three disciplines known as "Improved PNFP ", "Active PNFP" and "Intelligent PNFP" on the basis of their properties. They can be used as separately or collectively depending on their use. 
The improved PNFP defining polymer flexibility, gas barrier properties, temperature and moisture stability while, the latter two express antimicrobial activities and sensitivity [41].

In improved PNFP there are several types of polymer material using like Poly Amide (PA), nylons, polystyrene, EthyleneVinyl Acetate (EVA), copolymers, epoxy resins poly urethane, polyolefin, polyimides and Polyethylene Terephthalate (PET), Hydrate Alumina and Silicate [42-43].

The nanoclay in food packaging and coating are the polyamide, Montmorillonite (MMT) mostly used in the formation of shaping food materials used for packaging of fruits juices, dairy products, cheese, cereals etc [44-45]. Clay polymer were single layer of clay are folded into a polymer system to create a new structure which is called exfoliated structure or nanocomposites prevent the passing of oxygen and water. Massachusetts university scientist of USA Julian $\mathrm{McCl}$ elements converts the single layer concept into double layer or multi-layer where each layer have unique functionality, for example one layer work as an antioxidant, antimicrobial activity indicator while the other layer indicates passage of water, oxygen, carbon dioxide. This concept is also being used in nano-lamination which consists of two or more layers of nanomaterials which are bound to each other and used for surface coating/ films and packaging. Edible coating and films are currently using in a wide range of fruits, vegetables, meats, chocolates, candies, and bakery products [46]. The coating film can serve as moisture, lipid, gas barriers so that to improve color, flavor, and nutrition, antimicrobial and oxidation reduction properties of coated food. The composition, thickness, structure of the single and multilayer depends on skill and sort of way like changing the dipping solution, adsorbing substances, number of dipping steps, the environmental condition of the solution, $\mathrm{pH}$, temperature and concentration of the solution while it also depends upon nature of substance to be coated either it is polar, nonpolar, hydrophobic, hydrophilic, etc.

Active PNFP food packagings are made to maintain the internal environment of the food regularly by means of preventing absorption and elimination to the inner and outer coating surface [47]. Such types of polymers are designed to monitor microbe activity, UV strength and absorption etc. Several particles using as antimicrobial agents like titanium dioxide, zinc oxide, magnesium oxides, they are also reported as UV blocker and photo catalytic disinfecting agents [48]. Titanium dioxide also plays important role in oxygen scavenging because the presence of oxygen in container causes red-ox reaction and it will also play a role in the growth of aerobic bacteria which can lead to the contamination of food [49].

The intelligent or smart PNFP which determining the surrounding and internal temperature, humidity, oxygen level and microorganism contamination of the packed food. The nanopolymer devices biosensors are incorporated in packing which alerts the consumer about the internal condition of the packed food, shelf life, food spoilage, color and event test [50]. Process under investigation on electronic tongue, DNA-based biochip which will be able to detect the harmful microbes quantity and type of microbes, color and test of the food [26].

\section{Antimicrobial packaging}

Several nano materials are used as antimicrobial agents in food packing in which silver Nanoparticles are in great interest. This is because of its extended use and from its historical perspective. Some other Nanoparticles currently in used are titanium dioxide $\left(\mathrm{TiO}_{2}\right)$, Zinc Oxide ( $\left.\mathrm{ZnO}\right)$, Silicon Oxide $\left(\mathrm{SiO}_{2}\right)$, Magnesium Oxide (MgO), gold, silver etc. All of them have specific characteristics and functions, for example zinc nanocrystal shows antimicrobial and antifungal activity [51], silver zeolite and silver, gold has high temperature stability and low volatiling and good antifungal and antimicrobial effects against 150 different bacteria [52-53]. Silver was a disinfectant and sterilizing agent used by NASA and Russian Space station for water [11]. Silver has a broad spectrum in its antimicrobial activity and it has been reported that the microbial resistivity aspect of silver is lesser then other molecular antimicrobial agents [54]. FDA in 2009 approves the direct use of silver as disinfectant in commercial water at maximum level of 17 ug/ kg (FDA, 2009).

As these silver particles are in microns and providing an effective result against microorganisms. Some studies suggested that they have far much better impact in nano sizes. The antimicrobial effect of the silver particles is due to silver ion migrating from packaging materials to food in contact. Several silver based composites have been reported effective like chitosan-silver nanocomposites found effective against $E$. coli, $L$. monocytogenes and Staphylococcus aureus [55], and nano silver particles coated with Cellulose acetate phthalate also provided the same results [56]. It has also been found that matrix also play an important role in the migration of silver ions to carry out its antimicrobial activity [57]. Silver Nanoparticles (AgNPs) are found to be effective against various bacterial species like E. coli, Staphylococcus aureus, Bacillus anthracis, staphylococcus epidermidis, Enterococcus faecalis, Pseudomonas aeruginosa [58], Vibrio cholerae [59-60] and Bacillus subtilis [61]. The spectrum of fungi, which they have been shown their antifungal activity, includes Candida albicans, Aspergillus niger [62-63] and yeast [64], etc. AgNPs are also found to be effective against methicillinresistant Staphylococcus aureus [58].

Besides silver several other nanoparticles are also found to have antimicrobial characteristics like titanium oxide $\left(\mathrm{TiO}_{2}\right)$, which shows its antimicrobial activity in UV light [65]. Curcumin Nanoparticles with $2-40 \mathrm{~nm}$ freely dispersed in water are reported to be effective against Staphylococcus aureus, Bacillus subtilis, Escherichia coli, Pseudomonas aeruginosa, Penicillium notatum and Aspergillus niger [66]. Zinc oxide is also found to have its antimicrobial activity which incorporated in packaging material [42]. Some complex systems of Nanoparticles like vancomycin covalently attached with gold Nanoparticles [67], polystyrene Nanoparticles which are coated with lysozyme along with selective antibodies are also found to have some promising results.

\section{Risks in Food Nanotechnology}

We are not forgetting the importance of nanotechnology in food packaging but it might be fatal to human body. In 20th 
century tremendous progress has been made in the field of nano sciences but still it needs more explorations.

The use of nanomaterial in food nanotechnology may exhibit possibility of health risks [68]. European Food Safety Authority (EFSA) has identified some major risks with nanotechnology i.e., characterization difficulty, detection and measuring nanomaterial and insufficient toxicological data (EFSA, 2009). Nanomaterial of small size ranging from 50 to $70 \mathrm{~nm}$ like carbon nanotube, silver, silica, titanium dioxide and zinc oxide etc. do not show exact mechanism inside the body. Nanotoxicity of nanoparticles depends on chemical structure, composition, size, mass, surface charges, and their combine relationship [6,69,70]. The range of penetration, translocation, digestion, accumulation of nanoparticles inside the human body is determinable risk factors. Although previous research shows that Nanoparticles of 50 to $70 \mathrm{~nm}$ can easily cross the cell barrier while smaller size of $30 \mathrm{~nm}$ cross the blood cell barriers and easily penetrate and circulate through the circulatory system of blood and respiratory system which may affect lungs, stomach, liver, spleen, bone marrow, heart and even brain function [8].

Food digestion study shows that nano-size food particles have greater chances to enter the gut. Particles are large as $200 \mathrm{~nm}$ can pass through the mucus membrane when coated with polyethylene glycol commonly used in drug coatings [6]. It has been reported that carbon nanotubes used in food packaging when examined in mice trachea lead to death [69]. The nanoparticles usually make nanofood are mostly oxidase of silicon, aluminums and titanium. These particles i.e. titanium dioxide (anatase (E 171)) and aluminosilicates (kaolinite) are used as food additives and anticaking agent [71]. It has been proved that titanium dioxide Nanoparticles of $20 \mathrm{~nm}$ make free radicals thus causing intracellular damage and inflammatory responses when inhale or penetrate by skin in insoluble form [70]. Titanium dioxide and aluminosilicates partially or not degraded in GIT (Gastro intestinal tract). In case of non-degradation M-Cells (microfold cells) of the immune system activated which stimulate macrophages. Macrophages are also unable to digest them thus makes pigmentation in cells at the base of human intestinal lymphoid aggregates due to partially agglomeration [72]. It has been proved that exogenous Nanoparticles of 100 $\mathrm{nm}$ in diameter are 15-250 times higher absorbable as compare to macromolecules in GIT [73]. It has been shown that single walled carbon nanotubes inhibit human embryo kidney cell proliferation and negative impact upon the cell growth and turnover [74]. A study of human epithelial cell culture in vitro while using fluorescence-labeled $\mathrm{SiO}_{2}$ nanoparticles showed that particle smaller than $70 \mathrm{~nm}$ could enter into the cell nuclei and cause impairment in the DNA replication and transcription due to the toxic protein accumulation, but it is not yet clear about the use of $\mathrm{SiO}_{2}$ in food packaging either it causes health problems.

The main point which is still unclear in food nanotechnology is that either the nano made food properties are similar or dissimilar as compared to the naturally founded food in the digestive system. It is clear that Nanoparticles will pass through agglomeration, aggregation, biotransformation and react with acid, enzyme and other chemicals in the body especially in GIT where they might lose their "Nano" specification [5]. Except few cases of toxicology research and risk assessment in nanotechnology there is no clear evidence of toxicity found in food packaging [12 -17]. A survey report shows that most of people are not fully acquainted with the term nanotechnology [75-76]. Some of the nano food production companies do not show possible risks of nanotechnology to the public [77]. In order to explore more nanotechnology, it is needed to show the beneficial as well as harmful aspects to the consumers. The first generation nanotechnology faces multi challenges in food sector due to the multi unknown characteristics of Nanoparticles like when we are using silver, zinc, gold etc either we know the migration of this Nanoparticles into food? If, then what will be the effect on the normal microbial flora of gastrointestinal track?

\section{Conclusion}

Nanotechnology is becoming an important part of food science and it is increasingly providing important applications to raise the food safety level. In comparison with the traditional food analytical tools nano-biosensor provide a quick and reliable method of analysis. In future it may seem that the food quality control and analysis would be replaced by the nanotechnology introduced nano-biosensors. The polymeric coating of nanobiosensors is arising as a new generation of packaging. Secondly the nano antimicrobial agents also provide promising results to control the contamination in food and the research is elaborating in the polymeric incorporation of these antimicrobial agents for active packaging. Nowadays, the concept of smart packaging is not a concealed theme, but it should be provided to public in such way that it can fulfill the food safety. The exploration about the risk influences should be improved to increase the consumer acceptance of nanotech processed food products.

\section{References}

1. Luis M. Liz-Marzán., Prashant V. Kamat. Nanoscale materials. 2005; 1-3 ISBN: 978-1-4020- 7366-3 (Print) 978-0-306-48108-6.

2. Bawa R, Bawa SR, Maebius SB, Flynn T, Wei C. Protecting new ideas and inventions in nanomedicine with patents. Nanomedicine. 2005; 1(2): 150-158.

3. Buzby JC. Nanotechnology for food applications more questions than answers. The Journal of consumer affairs.2010; 44(3): 528-545.

4. Chinnamuthu CR, Murugesa BP. Nanotechnology and Agroecosystem. Madras Agric J. 2009; 96 (1-6): 17-31.

5. Siegrist M, Nowackv B, Kastenholz H. Environmental Considerations of and Societal Reactions to Nanotechnology in the Food Sector. In: LJ. Frewer, W Norde, ARH. Fischer, FWH. Kamper (Eds.), Nanotechnology in the Agri-Food Sector. John Wiley \& Sons: p. 209-223.

6. Semo E, Kesselman E, Danino D, Livney YD. Casein micelle as a natural nano-capsular vehicle for nutraceuticals. Food Hydrocolloids.2007; 21(1-6): 936-942.

7. Bhupinder SS. Food nanotechnology-an overview. Nanotechnol Sci Appl. 2010; 3: 1-15.

8. Graveland B, JF de Kruifa CG. Unique milk protein based nanotubes: Food and nanotechnology meet. Trends in Food Science \& Technology. 2006; 17: 196-203. 
9. Nel A, Xia T, Mädler L, Li N. Toxic potential of materials at the nanolevel. Science. 2006; 311(5761): 622-7.

10. Verma ML, Barrow CJ, Kennedy JF, Puri M. Immobilization of $\beta$-dgalactosidase from Kluyveromyces lactis on functionalized silicon dioxide nanoparticles: Characterization and lactose hydrolysis. Int J Biol Macromol. 2012 M; 50(2): 432-7. doi: 10.1016/j. ijbiomac.2011.12.029.

11. Duncan TV. Applications of nanotechnology in food packaging and food safety: barrier materials, antimicrobials and sensors. J Colloid Interface Sci. 2011 Nov 1; 363(1): 1-24. doi: 10.1016/j. jcis.2011.07.017.

12. Tiede K, Boxall AB, Tear SP, Lewis J, David H, Hassellov M. Detection and characterization of engineered nanoparticles in food and the environment. Food Addit Contam Part A Chem Anal Control Expo Risk Assess. 2008 Jul; 25(7): 795-821. doi: 10.1080/02652030802007553.

13. Otles S, Yalcin B. Review on the application of nanobiosensors in food analysis. Acta Sci Pol Technol Aliment. 2012 Jan-Mar; 11(1): 7-18.

14. Rana JS, Jindal J, Beniwal V, Chhokar V. Utility biosensors for applications in agriculture-A Review. J Am Sci. 2010; 6(9): 353-375.

15. Ying Li, Jingyue Xu and Chunyan Sun. Chemical sensors and biosensors for the detection of melamine. RSC Adv. 2015; 5: 1125-1147.

16. Ai K, Liu Y, Lu L. Hydrogen-bonding recognition-induced color change of gold nanoparticles for visual detection of melamine in raw milk and infant formula. J Am Chem Soc. 2009; 131(27): 9496-7. doi: 10.1021/ ja9037017.

17. Card JW, Magnuson BA. A method to assess the quality of studies that examine the toxicity of engineered nanomaterials. Int J Toxicol. 2010; 29(4): 402-10. doi: 10.1177/1091581810370720.

18. Koedrith P, Thasiphu T, Weon JI, Boonprasert R, Tuitemwong K, Tuitemwong P. Recent Trends in Rapid Environmental Monitoring of Pathogens and Toxicants: Potential of Nanoparticle-Based Biosensor and Applications. Scientific World Journal. 2015; 2015: 510982. doi: $10.1155 / 2015 / 510982$.

19. Vamvakaki V, Chaniotakis NA. Pesticide detection with a liposomebased nano-biosensor. Biosens Bioelectron. 2007; 22(12): 2848-53.

20. Malhotra BD, Srivastava S, Azahar Ali MD, Chandan S. NanomaterialBased Biosensors for Food Toxin Detection . Appl Biochem Biotechnol .2014; 174(3): 880-896.

21. Warner MG, Grate JW, Tyler A, Ozanich RM, Miller KD, Lou J, Marks JD, et al. Bruckner-Lea. Quantum dot immunoassays in renewable surface column and 96-well plate formats for the fluorescence detection of botulinum neurotoxin using high-affinity antibodies. Biosens Bioelectron. 2009; 25(1): 179-84. doi: 10.1016/j.bios.2009.06.031.

22. Mishra NN, Maki WC, Cameron E, Nelson R, Winterrowd P, Rastogi SK. Ultra-sensitive detection of bacterial toxin with silicon nanowire transistor. Lab Chip. 2008; 8(6): 868-71. doi: 10.1039/b802036a.

23. Martínez-Castañón GA, Niño-Martínez N, Martínez-Gutierrez F, Martínez-Mendoza JR, Martínez-Mendoza FR, Facundo R. Synthesis and antibacterial activity of silver nanoparticles with different sizes. Journal of Nanoparticle Research. 2008; 10(8): 1343-1348.

24. Mills A. Oxygen indicators and intelligent inks for packaging food. Chem Soc Rev. 2005; 34(12): 1003-11.

25. Eby DM, Schaeublin NM, Farrington KE, Hussain SM, Johnson GR. Lysozyme catalyzes the formation of antimicrobial silver nanoparticles. ACS Nano. 2009; 28(4): 984-94.
26. Liu Y, Chakrabartty S, Alocilja E. Fundamental building blocks for molecular biowire based forward error-correcting biosensors. Nanotechnology. 2007; 18(42): 424017. doi: 10.1088/09574484/18/42/424017.

27.Zhang WH, Zhang WD. Fabrication of SnO2-ZnO nanocomposite sensor for selective sensing of trimethylamine and the freshness of fishes. Sensors and Actuators B: Chemical. 2008; 134: 403-408.

28. Yootana Pimtong-Ngama, Sirithan Jiemsirilersb, Sitthisuntorn Supothina. Preparation of tungsten oxide-tin oxide nanocomposites and their ethylene sensing characteristics. Sensors and Actuators A: Physical. 2007; 139(1-2): 7-11.

29. Fayaz AM, Balaji K, Girilal M, Yadav R, Kalaichelvan PT, Venketesan R. Biogenic synthesis of silver nanoparticles and their synergistic effect with antibiotics: a study against gram-positive and gramnegative bacteria. Nanomedicine. 2010; 6(1): 103-9. doi: 10.1016/j. nano.2009.04.006.

30. Jain KK. Nanotechnology in clinical laboratory diagnostics. Clin Chim Acta. 2005 ; 358(1-2): 37-54.

31. Rosi NL, Mirkin CA. Nanostructures in biodiagnostics. Chem Rev. 2005; 105(4): 1547-1562.

32. Elghanian R, Storhoff JJ, Mucic RC, Letsinger RL, Mirkin CA. Selective colorimetric detection of polynucleotides based on the distancedependent optical properties of gold nanoparticles. Science. 1997; 277(5329): 1078-81.

33. Grossman HL, Myers WR, Vreeland VJ, Bruehl R, Alper MD, Bertozzi CR, et al. Detection of bacteria in suspension by using a superconducting quantum interference device, Proc Natl Acad Sci U S A. 2004; 101(1): 129-34.

34. Ozdemir M, Floros J. D. Active food packaging technologies. Crit Rev Food Sci Nutr. 2004; 44(3): 185-93.

35. Brody AL. Nanocomposites technology in food packaging. Food Technol. 2007; 61: 80-3.

36. Esposito E, Cortesi R, Drechsler M, Paccamiccio L, Mariani P, Contado C, et al. Cubosome dispersions as delivery systems for percutaneuos administration of indomethacin. Pharm Res. 2005; 22(12): 2163-73.

37. Lagaron JM, Gimenez E, Sánchez-García MD, Ocio MJ, Fendler A. Novel nanocomposites to enhance quality and safety of packaged foods. In: Food contact polymers Technologies. 2007; 19: 1-5.

38. Brody AL. Nano and food technology converge. Food Technol. 2003; 60: $92-4$.

39. Chaudhry Q, Scotter M, Blackburn J, Ross B, Boxall A, Castle L, et al. Applications and implications of nanotechnologies for the food sector. Food Addit Contam Part A Chem Anal Control Expo Risk Assess. 2008; 25(3): 241-58. doi: 10.1080/02652030701744538.

40. Sorrentino A, et al. Potential perspectives of bio nanocomposites for food packaging applications. Trends Food Sci. Technol. 2007; 18(2): 84-95.

41. Clara Silvestre, Donatella Duraccio, Sossio Cimmino. Food packaging based on polymer nanomaterials. Progress in Polymer Science. 2011; 36(12):1766-1782.

42. Paula Espitia, Nilda de Fátima Ferreira Soare, Jane Coimbra, Nélio José de Andrade, Renato Souza Cruz, Eber Antonio Alves Medeiros. Zinc Oxide Nanoparticles: Synthesis, Antimicrobial Activity and Food Packaging Applications. Food and Bioprocess Technology. 2012; 5(5): 1447-1464. DOI: 10.1007/ s11947-012-0797-6. 
43. Paiva, LB, Morale AR, Diaz FRV. Organoclays: properties preparation and applications. Appl Clay Sci. 2008; 42(1-2): 8-24.

44. Bharadwaj RK, Mehrabi AR, Hamilton C, Trujillo C, Murga M, Fan R, et al. Structure property relationships in cross linked polyester clay nanocomposites. Polymer. 2002; 43(13): 3699-3705.

45. Weiss J, Takhi stov P, Mcclements, DJ. Functional materials in food nanotechnology. J Food Sci. 2006;71(9):107-116. DOI: 10.1111/ j.1750-3841.2006.00195.x.

46. Avella M, De Vlieger JJ, Errico ME, Fischer S, Vacca P, \& Volpe MG Biodegradable starch/clay nanocomposite films for food packaging applications. Food Chemistry. 2005; 93(3): 467-474.

47. Arora A \& Padua GW. Review: nanocomposites in food packaging. J Food Sci. 2005; 75(1): 43-49. doi: 10.1111/j.1750-3841.2009.01456.x.

48. Fujishima A, Rao TN, Tryk DA. Titanium dioxide photocatalysis. J Photochem Photobiol C. 2000;1(1):1-21.

49. Balazs AC, Singh C, Zhulina E. Modeling the interactions between polymers and clay surfaces through self-consistent field theory. Macromolecules. 1998; 31(23): 8370-8381. DOI: 10.1021/ ma980727w.

50. Bhattachary S, et al. Biomems and nanotechnology based approaches for rapid detection of biological entities. J. Rapid Methods Auto Microb. 2007; 15:1-32.

51. Vermeiren L, Devlieghere F, Debevere J. Effectiveness of some recent antimicrobial packaging concepts. Food Addit Contam A. 2002; 19 Suppl: 163-171.

52. Kumar R, Münstedt H. Silver ion release from antimicrobial polyamide/ silver composites. Biomaterials. 2005; 26(14): 2081-2088.

53. Liau SY, Read DC, Pugh WJ, Furr JR, Russell AD. Interaction of silver nitrate with readily identifiable groups: relationship to the antibacterial action of silver ions. Lett Appl Microbiol. 1997; 25(4): 279-283.

54. Chopra I. The increasing use of silver-based products as antimicrobial agents: a useful development or a cause for concern? J Antimicrob Chemother. 2007; 59(4): 587-590.

55. Catalina Marambio-Jones, Eric MV Hoek. A review of the antibacterial effects of silver nanomaterials and potential implications for human health and the environment. J Nano part Res. 2010; 1(5)2: 1531-1551. DOI: 10.1007/ s11051-010-9900-y.

56. Necula A. M, Dunca S, Stoica I, Olaru N, Olaru L, \& Ioan S. Morphological properties and antibacterial activity of nano-silver containing cellulose acetate phthalate films. International Journal of Polymer Analysis and Characterization. 2010; 15(6): 341-350. DOI: 10.1080/ 1023666X.2010.500524.

57. Elsa Lloret, Pierre Picouet, Avelina Fernández. Matrix effects on the antimicrobial capacity of silver based nanocomposites absorbing materials. Food Science and Technology. 2012; 49(2): 333-338.

58. Panacek A, Kvítek L, Prucek R, Kolar M, Vecerova R, Pizúrova N, et al. Silver colloid nanoparticles: synthesis, characterization, and their antibacterial activity. J Phys Chem B. 2006; 110(33): 16248-16253.

59. Sarkar S, A. D. Jana, S. K. Samanta, and G. Mostafa. Facile synthesis of silver nano particles with highly efficient anti-microbial property. Polyhedron. 2007; 26(15): 4419-4426.

60. Morones JR, Elechiguerra JL, Camacho A, Holt K, Kouri JB, Ramírez JT, et al. The bactericidal effect of silver nanoparticles. Nanotechnology. 2005; 16(10): 2346-53. doi: 10.1088/ 0957-4484/ 16/10/059.
61. Yoon KY, HoonByeon J, Park JH, Hwang J. Susceptibility constants of Escherichia coli and Bacillus subtilis to silver and copper nanoparticles. Sci Total Environ. 2007; 373(2-3): 572-575.

62.Egger S, Lehmann RP, Height MJ, Loessner MJ, Schuppler M. Antimicrobial properties of a novel silver-silica nanocomposite material. Appl Environ Microbiol. 2009; 75(9): 2973-2976. doi: 10.1128/ AEM.01658-08.

63. Sánchez Valdes S, Ortega-Ortiz H, Ramos-de Valle L. F, Medellín Rodríguez F. J, Guedea Miranda. R. Mechanical and antimicrobial properties of multilayer films with a polyethylene/silver nanocomposite layer .Journal of Applied Polymer Science. 2009; (2)111:953-962. doi: 10.1002/ app.29051.

64. Kim JS, Kuk E, Yu KN, Kim JH, Park SJ, Lee HJ, et al. Antimicrobial effects of silver nanoparticles. Nanomedicine.. 2007; 3(1): 95-101.

65. Kim B, Kim D, Cho D, Cho S. Bactericidal effect of TiO2 photocatalyst on selected food-borne pathogenic bacteria. Chemosphere. 2003; 52(1): 277-281.

66. Bhawana, Basniwal RK, Buttar HS, Jain VK, Jain N. Curcumin nanoparticles: preparation, characterization, and antimicrobial study. J Agric Food Chem. 2011; 59(5): 2056-2061. doi: 10.1021/jf104402t.

67. Hongwei Gu, Keming $\mathrm{Xu}$, Chenjie $\mathrm{Xu}$ and Bing Xu. Biofunctional magnetic nanoparticles for protein separation and pathogen detection. Chem Commun. 2006; 9: 941-949. DOI: 10.1039/ B514130C.

68. M. Cushen, J. Kerry, M. Morris, M. Cruz-Romero and E. Cummins. Nanotechnologies in the food industry recent developments, risks and regulation. Trends in Food Science \& Technology.2012; 24(1): 30-46.

69. Chi-Fai Chau, Shiuan-Huei Wu and Gow-Chin Yen. The development of regulations for food nanotechnology. Trends in Food Science \& Technology. 2007; 18(5): 269-280.

70. Oberdorster G, Sharp Z, Atudorei V, Elder A, Gelein R, Lunts A, et al. Extra pulmonary translocation of ultrafine carbon particles following whole-body inhalation exposure of rats. J Toxicol Environ Health A. 2002; 65(20): 1531-1543.

71.Lomer MC, Harvey RS, Evans SM, Thompson RP, Powell JJ. Efficacy tolerability of a low microparticle diet in a double blind randomized pilot study in Crohn's disease. Eur J Gastroenterol and Hepatol. 2001;132(2): 101-106.

72. Powell JJ, Harvey RS, Ashwood P, Wolstencroft R, Gershwin ME, Thompson RP. Immune potentiation of ultrafine dietary particles in normal subjects patients with inflammatory bowel disease. J Autoimmun. 2000; 141(1): 99-105.

73. des Rieux A, Fievez V, Garinot M, Schneider YJ, Preat V. Nanoparticles potential oral delivery systems of proteins vaccines: A mechanistic approach. J Control Release. 2006; 116(1): 1-27.

74. Cui D, Tian F, Ozkan CS, Wang M, \& Gao H. Effect of single wall carbon nanotubes on human HEK293 cells. Toxicol Lett. 2005; 155(1): 73-85.

75. Cobb M. D, \& Macoubrie J. Public perceptions about nanotechnology: Risks, benefits and trust. Journal of Nanoparticle Research. 2004; 6(4): 395-405. DOI: 10.1007/ s11051-004-3394-4.

76. Scheufele DA, Lewenstein BV. The public and nanotechnology: How citizens make sense of emerging technologies. Journal of Nanoparticle Research. 2005; 7(6): 659-667.

77. Helland A, Scheringer M, Siegrist M, Kastenholz HG, Wiek A, \&Scholz RW. Risk assessment of engineered nanomaterials Survey of industrial approaches. Environ Sci Technol. 2008; 42(2): 640-646. 